\title{
Discursos de la guerra en Colombia 1998-2005
}

\section{VICTORIA ELENA \\ GONZÁLEZ MANTILLA}

Comunicadora social-periodista de la Universidad Externado de Colombia. Especialista en Comunicación-educación de la Universidad Central. Con estudios de maestría en Literatura Latinoamericana. Candidata a doctora en Ciencias sociales de la Universidad Nacional de General Sarmiento / IDES. Coordinadora del énfasis de periodismo de la Facultad de Comunicación social y periodismo de la Universidad Externado de Colombia.

Correo-e: victoria.gonzalez@uexternado.edu.co

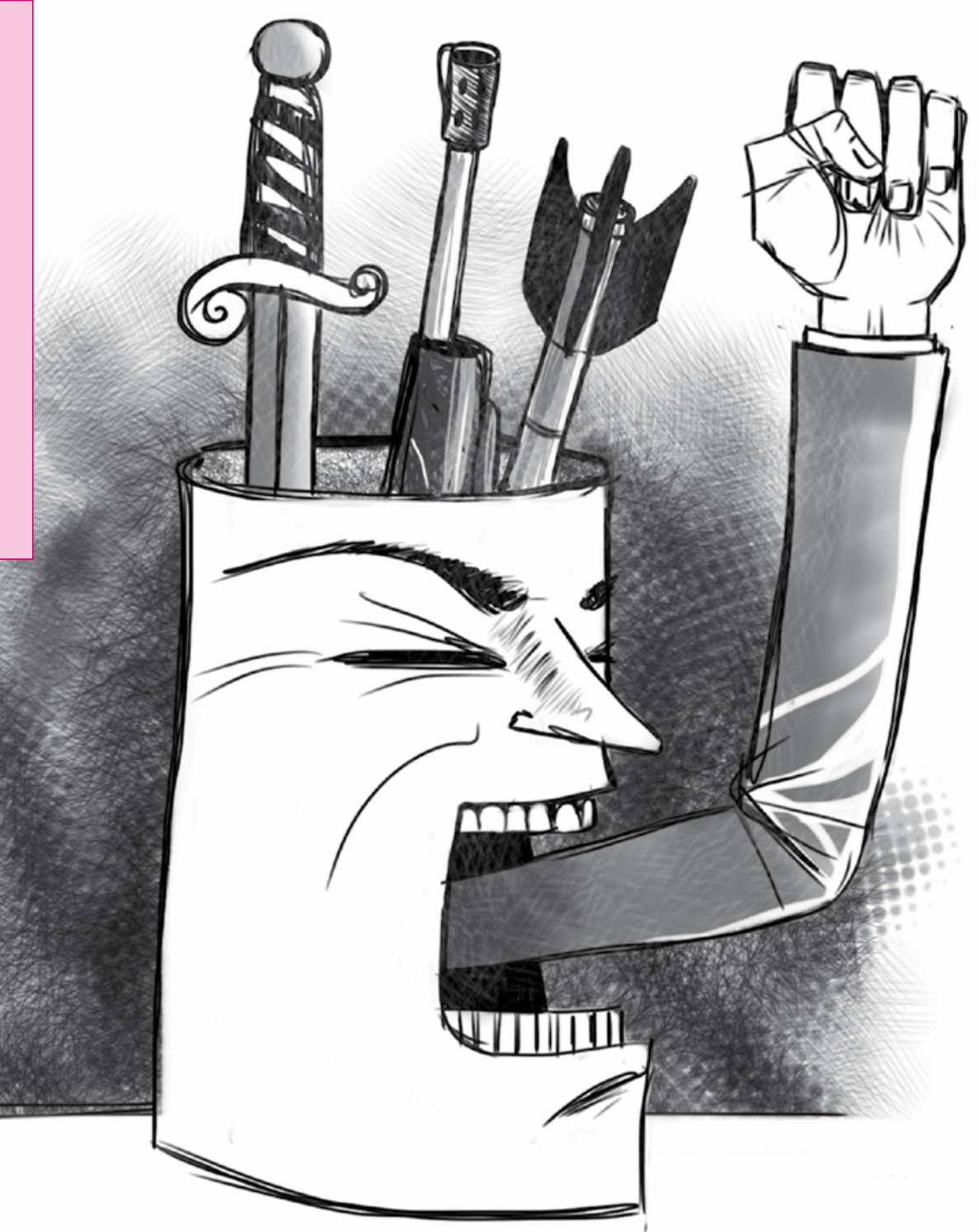

\section{RESUMEN}

El presente artículo hace parte de la investigación de tesis Discursos de la guerra en Colombia 19982005 realizada en el marco del Doctorado en Ciencias Sociales de la Universidad Nacional de General Sarmiento/IDEs, Buenos Aires.

Palabras clave: Guerra posmoderna; Discurso; Colombia.

\section{ABSTRACT}

This article is part of the thesis research Speeches 1997-2005 war in Colombia conducted under the PhD in Social Sciences at the National University of General Sarmiento / IDEs, Buenos Aires.

Keywords: War Postmodern; Discourse; Colombia. 
$\mathrm{L}$ a excepcional duración en el tiempo, las peculiaridades de su desarrollo y la metamorfosis que ha tenido, tanto en los accionares internos como en el contexto internacional, son algunas de las características de la guerra colombiana que la han convertido en un fenómeno de alta complejidad en el que se entrelazan múltiples elementos.

En muchas oportunidades, las acciones violentas contra la población civil, las disputas territoriales, los enfrentamientos entre grupos armados y el desplazamiento interno se asumen como los únicos componentes que desempeñan un papel importante en un conflicto. Esto se debe quizá al carácter tangible que poseen y que les permite hacer parte de las estadísticas en los bancos de datos o alimentar las noticias que presentan a diario los medios de comunicación. Pero, ¿qué sucede con otros elementos igualmente significativos como son los discursos de los actores del conflicto difundidos en comunicados, declaraciones y cartas que circulan permanentemente? ¿Qué importancia tienen dentro de la estrategia de acción política utilizada por parte de los diferentes actores involucrados? ¿Cuáles son los mensajes y sentidos que los actores hacen circular en sus discursos?

Para esta investigación elegimos un corpus de 28 registros producidos entre 1998 y 2005 por tres actores discursivos: las AUC, las FARC y representantes del gobierno de Andrés Pastrana y Álvaro Uribe Vélez, incluidos los dos mandatarios. Con esos registros elaboramos una especie de tejido procesado con los patrones de la historicidad en el análisis crítico del discurso liderado por la investigadora austriaca Ruth Wodak. De esta manera, pudimos leer en la muestra dos etapas históricas del país. Dos procesos de paz con dos grupos armados distintos y la perspectiva mediática frente a acontecimientos que atravesaron esas prácticas discursivas producidas en esas dos etapas. El resultado es un análisis que nos permite ver la guerra en Colombia no solo desde cifras o desde el testimonio de víctimas y victimarios, sino desde los discursos de los actores que en ella intervienen en un gran marco que nos brinda múltiples elementos para comprender la guerra más allá de las palabras.

La construcción del estado del arte de esta investigación se hizo mediante una exploración de más de cincuenta años de literatura que se organizó cronológicamente. Tomamos además en un aparte especial las producciones relacionadas con medios de comunicación, discurso y conflicto.

\section{LOS EJES TEMÁTICOS}

Consideramos que un trabajo investigativo que pretenda dar cuenta de los Discursos de la guerra en Colombia entre 1997 y 2005 debe mirar dos ejes temáticos: el que atiende a los diferentes conceptos que existen alrededor de lo que significa discurso y el que explica categorías como guerra civil, conflicto armado, violencia y terrorismo, entre otros.

Sobre el eje discurso - mirando en particular el análisis crítico del discurso y dentro de esta línea, la historicidad- encontramos puntos en común entre los autores que nos permiten pensar el discurso, tal como lo expone Foucault, teniendo en cuenta los ámbitos institucionales desde los que se produce y las posiciones del sujeto; también, tal como lo propone Teun van Dijk, desde varios niveles de estructura como la sintaxis, la semántica, la estilística y la retórica. Igualmente, desde el estudio de géneros como la argumentación y la narración de historias, y desde los procesos cognitivos concretos de su producción y comprensión por parte de los usuarios del lenguaje. Del mismo modo, creemos fundamental entender el discurso como práctica social y cultural, teniendo en cuenta los planteamientos de Ruth Wodak, quien afirma que las determinaciones situacionales, institucionales y sociales configuran los discursos y los afectan, y los discursos influyen en las acciones y los procesos sociales y políticos de carácter discursivo y de carácter no discursivo.

Con respecto al segundo eje en el cual buscamos definir violencia, conflicto armado, guerra, etc., nos apartamos de las teorías deterministas que asumen la condición del colombiano como un sujeto proclive a la violencia. Igualmente, nos oponemos radicalmente a quienes niegan la existencia de una guerra en Colombia e incluso de un conflicto armado y que denominan la situación más bien como una "guerra contra el terror". Tampoco compartimos la idea de quienes reducen la situación colombiana a la existencia de grupos armados ilegales que operan en el territorio nacional, ya que el accionar de estos grupos va mucho más allá de las confrontaciones armadas periódicas.

Consideramos que la situación colombiana tiene las características propias de una guerra posmoderna o postclausewitziana, propuesta por el analista Jorge Giraldo (2009) quien en su libro Guerra Civil posmoderna, luego de hacer un extenso recorrido por los autores que han trabajado los conceptos de guerra, guerra civil, conflicto armado, etc., define guerra posmoderna como:

Forma de guerra en la que el Estado deja de ser el único decisor respecto de la enemistad y el objetivo politico, y aparecen otras unidades políticas como 
competidoras suyas; la separación moderna de las funciones en la guerra atribuidas al gobierno, al ejército y al pueblo, se pierde y se crea una nueva unidad política, militar y pasional, en la figura del partisano; por consiguiente, las distinciones entre regular e irregular, militar y civil, público y privado, dentro y fuera, se hacen borrosas y, asi, la capacidad reguladora del derecho o, probablemente, de una moral compartida, pierde eficacia.

En relación con el conflicto armado, al autor explica que:

...la pretensión normativa de regular la guerra, se ahoga cuando se empieza por definir qué hechos y agentes reúnen los elementos necesarios para la categoría conflicto armado, confundiendo de nuevo los hechos empiricos con las instituciones modernas y aceptando como casos marginales de instituciones aquellos que se justifican a partir de valores modernos como la nación o la ciudadanía (ídem).

A esta guerra posmoderna o postclausewitziana se han ido sumando, tal como lo expone Münkler (2005), nuevos actores y perversas modalidades propias de los tiempos que vivimos.

En lo relativo a modalidades, reconocemos en esa guerra moderna actos de genocidio, representados en decenas de masacres acaecidas en varios lugares del país producidos por grupos armados de derecha; actos terroristas, realizados principalmente por grupos armados de izquierda, y actos de terror, propiciados por parte del Estado, que en los últimos años han cobrado la vida de varios ciudadanos utilizando estrategias como la denominada "falsos positivos".

Consideramos que la guerra posmoderna en Colombia ha tenido transformaciones a lo largo de cinco décadas, producto de la introducción de nuevas acciones, nuevos escenarios y nuevos actores, como el narcotráfico y el paramilitarismo. Del mismo modo, ha tenido fluctuaciones o picos propios de momentos políticos, sociales y económicos particulares, lo cual no significa que debamos negar el carácter de un fenómeno que aún no termina ni permite vislumbrar una solución definitiva.

1. Aunque la práctica es anterior, el término "falsos positivos" se usó por primera vez en febrero de 2007 cuando los oficiales del Ejército Javier Efrén Hermida y Luis Barrero fingieron haber evitado atentados explosivos con bombas en Bogotá, con el fin de obtener sendas recompensas por sus acciones, maniobra que fue descubierta posteriormente. En adelante se denominó de la misma manera a la desaparición y muerte de varios civiles ocurrida en distintos lugares del país, que posteriormente fueron reportados por el Ejército como muertos en combate sin que hubiese pruebas de que pertenecían a grupos armados.

\section{DESARROLLO DE LA INVESTIGACIÓN}

La construcción del minucioso marco histórico que hizo parte de esta investigación (19471997) obedeció principalmente a las exigencias de la opción interpretativa elegida para este trabajo: la historicidad del análisis crítico del discurso.

Con respecto al corpus elegido, denominamos corpus a una serie de textos provenientes de diversas fuentes determinadas por el objeto de la investigación, que presume una posición del investigador y unos intereses particulares.

La interpretación de esos datos implica la identificación de unas categorías y de unos recursos analíticos. Para la elección del corpus tenemos una primera pauta de delimitación que apunta a los discursos de tres actores dentro de la guerra (gobierno, AUC y FARC). Una segunda pauta es la delimitación temporal que nos circunscribe al lapso comprendido entre 1998 y 2005.

Sobre la elección de los actores, definimos actor dentro de la guerra mediante dos acepciones que Medios para la paz (2005) le da a actor del conflicto armado:

\section{Combatiente de una de las partes o también, quien en un conflicto tiene la capacidad de cam- biar sustancialmente su curso.}

Esta nominación se inscribe en la categoría actor, entendido como un agente-sujeto que cuenta con un conjunto de recursos materiales, capaz de una acción individual o colectiva. Las acciones, entre tanto, brindan los argumentos más importantes para caracterizar a los actores. La acción tiene tres aspectos, el físico, el cognitivo y el cultural, productos de formas de relación, ideologías o acumulados socioculturales de los individuos o comunidades, que permiten reconocer sus orígenes y propósitos. De lo anterior podemos deducir que la acción desempeña un importante papel en la categorización de los actores y en la construcción social de la realidad. De la interacción entre acción y actor social, que es la voz del discurso, surge la tercera categoría, denominada actor discursivo, que se entiende como:

Un ser cognitivo y social, que construye y reconstruye la realidad, generador de formas de representación del contexto en el que actúa y de si mismo, con lo cual crea, con los actores que lo rodean, formas de entender la realidad en el marco de un discurso con perspectivas histórica, social, política y cognitiva. El actor discursivo entonces es un sujeto que desempeña roles discursivos y que en su calidad de sujeto social construye una imagen de si mismo, del otro y de la realidad (Pardo, 2007). 
La elección del lapso 1998-2005 se justifica por la necesidad de dar relevancia a una etapa atravesada por dos procesos de paz con dos grupos armados confrontados militarmente. En dicha etapa se dan las transformaciones en las relaciones del gobierno del presidente Andrés Pastrana Arango con las Fuerzas Armadas Revolucionarias de Colombia -FARC-, a partir de las conversaciones previas al inicio de un proceso de paz fallido (1998) y la propuesta de ese proceso de paz con este grupo armado al inicio de la gestión de este mandatario en 1999. También se presenta el ascenso al poder del presidente Álvaro Uribe en 2002 y sus acuerdos con los grupos paramilitares mediante la Ley 975 de 2005.

En relación con la elección específica de las variedades discursivas objeto de análisis, se escogen dentro de un universo de hechos ocurridos en la etapa de la guerra colombiana comprendida entre 1998 y 2005, a los que hemos denominado acontecimientos. Justificamos la elección de unos acontecimientos, en menoscabo de otros, partiendo del reconocimiento de que todo trabajo que tiene una perspectiva histórica descompone el tiempo pasado y escoge entre sus realidades cronológicas, según preferencias más o menos conscientes del investigador.

En el marco de cada acontecimiento elegido, hemos seleccionado los siguientes tipos de variedades discursivas: comunicados, acuerdos y discursos políticos.

Estas variedades discursivas que constituyen los Discursos de la guerra en Colombia producidos durante una época determinada (1998-2005) se analizaron tomando como base un amplio marco teórico que nos brindó las herramientas para poder, desde el análisis cualitativo:

- Mirar la incidencia del trasfondo histórico en la constitución de las variedades discursivas de los diferentes actores teniendo en cuenta más de 60 años de guerra en el país.

- Considerando la información periodística producida alrededor del registro o del acontecimiento del que se habla en el mismo.

- Contemplando las teorías de rango medio, o variables extralingüísticas sociales o sociológicas y los marcos institucionales de un contexto de situación específico (Wodak, 2005).

- Incorporando las macroteorías, o amplios contextos sociopolíticos e históricos en los que están ubicadas las prácticas discursivas.

- Mirando la relación intertextual e interdiscursiva, entre las variedades discursivas elegidas en el corpus. Si quisiéramos expresar de manera gráfica la forma como hemos concebido este análisis podríamos utilizar el siguiente esquema:

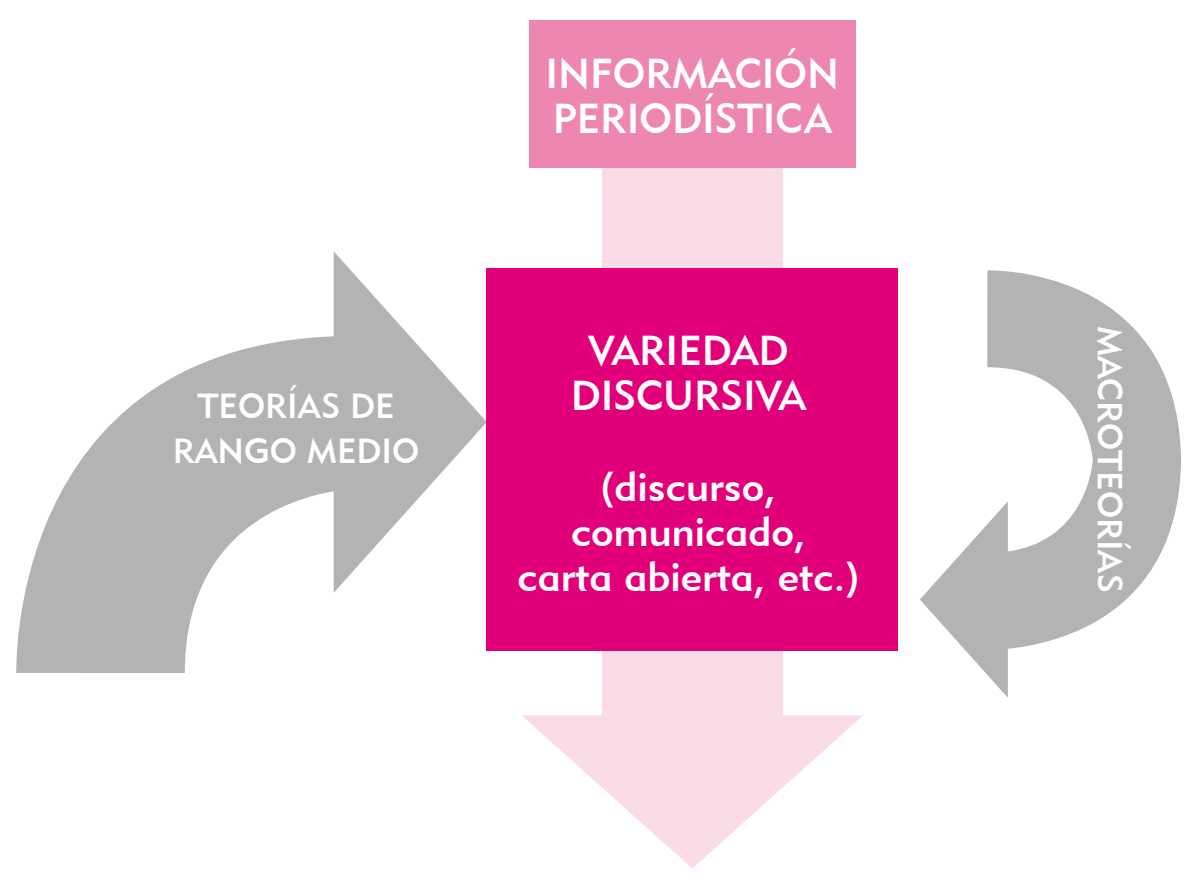


La matriz elaborada para hacer el análisis de este corpus se conformó de la siguiente manera:

\begin{tabular}{|c|c|c|c|c|c|}
\hline Fecha & Acontecimiento & $\begin{array}{c}\text { Documento(s) } \\
\text { que lo(s) registra }\end{array}$ & $\begin{array}{c}\text { Fecha de } \\
\text { registro }\end{array}$ & $\begin{array}{c}\text { Variedad } \\
\text { discursiva }\end{array}$ & $\begin{array}{c}\text { Actor } \\
\text { discursivo }\end{array}$ \\
\hline $\begin{array}{l}9 \text { de julio de } \\
1998\end{array}$ & $\begin{array}{l}\text { Andrés Pastrana y Ma- } \\
\text { nuel Marulanda Vélez, } \\
\text { "Tirofijo" se entrevistan } \\
\text { en algún lugar de las } \\
\text { montañas de Colombia }\end{array}$ & $\begin{array}{l}\text { Comunicado público } \\
\text { a extranjeros y colom- } \\
\text { bianos }\end{array}$ & $\begin{array}{l}12 \text { de julio } \\
\text { de 1998 }\end{array}$ & Comunicado & Las FARC \\
\hline
\end{tabular}

\section{Ejemplo de análisis}

El Estado Mayor del Bloque Oriental de las FARC-EP, informa a la opinión pública nacional $e$ internacional:

1. El Comandante Gildardo, del 10 Frente de las FARC-EP andaba en una comisión de reconocimiento de terreno, con 3 unidades más; al enterarse que habían entrado en la región de los indígenas U'was, unas personas desconocidas y sin autorización de la guerrilla; improvisó una comisión de investigación. $\mathrm{Al}$ encontrarlos, los capturó y ajustició sin consultar a los organismos superiores de dirección.

2. Dejamos claro que no es política de las FARC-EP, desaparecer colombianos o gente de otras nacionalidades.

3. Solicitamos, que cuando alguien vaya a penetrar a zonas de las FARC-EP, primero se identifique y pida autorización para evitar cualquier incidente a lamentar.

4. A ningún Estado entregaremos a nuestros combatientes. Al Comandante Gildardo, lo juzgamos y sancionamos de acuerdo a las leyes de las FARC-EP, consagradas en el reglamento de régimen disciplinario de la organización guerrillera.

Por el Estado Mayor del Bloque Oriental de las FARC-EP

Jorge Suárez Briceño.

Montañas de Colombia, marzo 10 de 1999

El 25 de febrero de 1999, los indigenistas Ingrid Washinawatok, Laheenae Gae y Terence Freitas fueron abordados saliendo del caserío El Chuscal, ubicado en el Departamento de Boyacá. Allí fueron interceptados por las Farc. Sus cuer- pos baleados fueron encontrados días después en Venezuela en el sector denominado Los Pájaros, cerca a la frontera con Colombia. Los indigenistas se encontraban viviendo con la comunidad indígena colombiana U'wa².

El comunicado está firmado por el Bloque Oriental de las FARC o "Bloque Comandante Jorge Briceño", una subdivisión de las FARC ${ }^{3}$. En el momento de emitir este comunicado este bloque estaba considerado como la facción militar más fuerte del este grupo guerrillero. Opera en las diferentes áreas de Colombia del oriente y centro del país. También se llama Jorge Briceño, debido a que estaba comandado por este dirigente guerrillero que murió en combate en 2010.

Está dirigido a la "opinión pública nacional e internacional". Se dirige no solo a la comunidad nacional sino también a la internacional, debido a las connotaciones diplomáticas que tuvo este acontecimiento. Está dividido en cinco puntos.

2. Los indígenas U'wa o Tunebos hacen parte de la macrofamilia lingüística Chibcha, una de las comunidades más grandes que se encontraba asentada en los Andes al arribo de los españoles. La comunidad estaba conformada por ocho clanes ubicados en la Sierra Nevada del CocuyGüicán, los cuales estaban subdivididos de acuerdo con su lugar de asiento en tierras altas, medias y bajas. Los primeros clanes desaparecieron al contacto directo con los españoles. Quienes sobrevivieron, fueron adscritos a instituciones coloniales como la encomienda, en las cuales se vieron sometidos a malos tratos, exceso de trabajo y escasa alimentación. Posterior al dominio español, los U'wa vivieron innumerables oleadas de colonización por parte de distintos grupos que quisieron apropiarse de sus tierras y de sus riquezas. Huyendo de esta situación llegaron incluso a ocultarse en montañas que bordean los 3.600 metros sobre el nivel del mar. De este modo, sobrevivieron durante varios años lejos del contacto con foráneos. Se calcula que en 1940 había unos veinte mil U'was quienes habitaban territorios que se extendían desde el sur de Venezuela hasta los departamentos de Arauca, Boyacá y Norte de Santander en el oriente colombiano. Hoy tan solo quedan cerca de cinco mil que ocupan prácticamente toda la vertiente nororiental de la Serranía del Cocuy.

3. Los bloques de las FARC están constituidos militarmente por 5 o más frentes. En ellos se coordinan y se unifican de forma estratégica todas las actividades de los frentes en una zona específica del país. Quien coordina las áreas de dichos bloques es el Secretariado o el Estado Mayor Central. 
En el primero de ellos informa: "El Comandante Gildardo, del 10 Frente de las FARC-EP andaba en una comisión de reconocimiento de terreno, con 3 unidades más; al enterarse que habían entrado en la región de los indígenas U'was, unas personas desconocidas y sin autorización de la guerrilla; improvisó una comisión de investigación. $\mathrm{Al}$ encontrarlos, los capturó y ajustició sin consultar a los organismos superiores de dirección”. Mencionan al comandante Gildardo, sin apellido, ya que es usual en la guerrilla dar nombres o alias a sus dirigentes que tan solo sirvan para una identificación interna. Sabemos que pertenece al Frente 10 de las FARC, que también es conocido como el Frente Guadalupe Salcedo, en honor al guerrillero muerto en los años cincuenta. Este frente hace parte del Bloque Oriental, por ello dicho bloque dirige el comunicado en cabeza de Jorge Briceño. Expone que Gildardo "andaba en una comisión de reconocimiento", es decir, en una labor militar en busca de explorar un territorio, y se entera de la incursión de "personas desconocidas en la región de los indígenas U'wa". La mención: "Personas desconocidas y sin autorización de la guerrilla", denota que el grupo armado tiene pleno dominio sobre esta región hasta el punto de reconocer a todos sus habitantes, pero además que quien ingrese al mismo territorio debe solicitar permiso, dado que las FARC fungen en el mismo como autoridad. La autoridad del grupo armado les permite "capturar" y "ajusticiar" a quienes sin autorización entren en este territorio, y esto es justamente lo que hacen las FARC, de acuerdo con el comunicado.

Podemos ver acá la macroteoría de Münkler (2005), quien afirma que:

En las nuevas guerras, el uso de la violencia se traslada de las fuerzas enemigas a la población civil; además, el paso que se da en el campo de batalla de las acciones violentas a la violencia difusa, no está relacionado con la decadencia de la disciplina de los guerreros sino que es producto de una juiciosa planificación.

Nos detenemos en el término "ajusticiar" para recordar que:

(...) la utilización de eufemismos no es patrimonio exclusivo de la oficialidad. De parte de los grupos armados también se usa este lenguaje metafórico por varias razones. La primera de ellas, por la necesidad de "normalizar" las acciones criminales para que no sean consideradas ilegales; la segunda, para lograr que a fuerza de reiteración estos vocablos se posicionen en el lenguaje común sin que se explore sus verdaderos sentidos o procedencias. La tercera, está relacionada con lo que Kurt y Katis Spillman denominan el sindrome del enemigo, es decir, "la mirada estereotipada del otro que conlleva una polarización elemental entre buenos (nosotros) / malos (ellos) y que incentiva a la deshumanización del oponente. Por ello, quienes cometen un crimen no pueden creer que estén ocasionando un daño irreparable a un ser humano como ellos (Spillmann, 1991). Como ejemplo de lo anterior vemos que las guerrillas colombianas convierten un secuestro en una "retención"; un robo de armas el ejército en una "recuperación"; una extorsión en una "vacuna" o un asesinato de los enemigos en un "ajusticiamiento". Del mismo modo, en sus "partes de guerra" se habla de "muertos en combate" o "dados de baja" (González, 2009).

Finaliza el párrafo explicando que la decisión del comandante Gildardo se tomó motu proprio y sin consultar a sus superiores. De igual manera, se justifica que si hubiese sido una decisión de la cúpula del grupo armado, el acto sería correcto.

A continuación el comunicado aclara que las FARC "no tienen como política desaparecer colombianos o gente de otras nacionalidades", lo cual indica que lo ocurrido con los indigenistas fue un hecho fortuito y no una "política de Estado", es decir el Estado o más bien paraestado establecido por las FARC en algunos territorios del país. Pero además no utilizar el término asesinar sino desaparecer para atenuar el impacto del mismo. En el punto número tres, el grupo armado solicita que aquellos que vayan a ingresar al territorio mencionado "pidan autorización", con lo cual reiteran que son las FARC las que ejercen el dominio, el control y la soberanía de este territorio y, por tanto, tienen potestad como autoridad para exigir la identificación de quienes se desplacen hasta allí.

En caso de que se desconozca esta autoridad, advierten que puede ocurrir nuevamente un hecho como el que se presentó. Lo anterior muestra una contradicción, dado que en apartes anteriores se da a entender que el hecho fue accidental. En el punto cuatro, las FARC manifiestan que "A ningún Estado entregaremos a nuestros combatientes. Al Comandante Gildardo, lo juzgamos y sancionamos de acuerdo a las leyes de las FARC-EP, consagradas en el reglamento de régimen disciplinario de la organización guerrillera".

Las FARC hablan de no entregar al combatiente Gildardo a ningún Estado, previendo que Estados Unidos se pronuncie por los asesinatos de sus nacionales y solicite a los culpables en extradición. Igualmente, hablan de juzgarlo y sancio- 
narlo de acuerdo con las leyes de las FARC, lo que denota la existencia de un aparato no solo militar sino también jurídico, dentro de este grupo armado que ejerce leyes particulares distintas a las del Estado colombiano. La sanción impuesta al comandante Gildardo por este delito podía ir desde la prohibición de participar en algunos cargos de dirección de la guerrilla, hasta el fusilamiento, según lo manifestó a la agencia de noticias ANNCOL el dirigente miembro del secretariado del grupo armado, Raúl Reyes el 9 de marzo de 1999. Posteriormente Olga Marín, compañera de Raúl Reyes, manifestó que el castigo para los culpables sería someterlos a trabajos comunitarios.

La revista Semana publicó en su edición del 12 de abril de 1999 que el gobierno de Washington tenía como prueba la intercepción de dos conversaciones radiotelefónicas. La primera del 28 de febrero, entre la radio-operadora de 'Grannobles', hermano del guerrillero Jorge Briceño conocido con el alias de 'Mono Jojoy', y la operadora radiotelefónica de este último en la que 'Grannobles' informa a su hermano que tiene en su poder a "tres gringos" que están haciendo daño a la comunidad U'wa y que, por tanto, lo mejor es matarlos. Y la segunda, sostenida dos días después, entre 'Grannobles' y 'Rafael', comandantes del décimo frente de las FARC, en la que 'Grannobles' dice:

Cuadren la vaina que el patrón autorizó lo de los gringos. Pero que debe hacerse eso al otro lado para no dejar rastros, porque el señor ordenó matar a los gringos en el lado venezolano (Semana, abril de 1999).

La trascendencia de este hecho se refleja en el contexto inmediato que produjo. En el plano internacional, por ejemplo, se da el pronunciamiento del presidente de la Comisión de Relaciones Internacionales de la Cámara de los Estados Unidos, Benjamin Gilman, representante del partido Republicano, quien le pidió al presi-

4. De acuerdo con informaciones de la Cadena Radial Caracol de Colombia emitidas el 14 de septiembre de 2002: "el Ejército abatió al autor material del asesinato de los tres indigenistas norteamericanos. En combates sostenidos en zona rural de Arauca, el ejército dio muerte a Gustavo Samanei Díaz, de 55 años, creador del frente 45 de las FARC, y a quien el Ejército responsabiliza de ser el autor de la muerte de los tres ciudadanos norteamericanos, Terence Freitas, Ingrid Washinawatoik y Larry Gai. Los operativos se registraron en zona rural de Fortul, donde murieron otros dos guerrilleros. Según el comandante de la segunda división, general Martín Orlando Carreño, dijo que Samanei Díaz recibió la orden directa de Germán Briceño, Alias Grannobles, para ejecutar a los tres extranjeros". dente Andrés Pastrana terminar las negociaciones de paz con las Farc. Del mismo modo lo hizo el presidente de la Comisión de Apropiaciones de la Cámara, el también republicano Dan Burton, quien afirmó que:

Estados Unidos debería concentrarse en suministrar las herramientas, tanto a la Policía como al Ejército, para que puedan derrotar a la guerrilla (El Tiempo, 15 de abril de 1999).

Por su parte, el Departamento de Estado de los Estados Unidos explicó que:

...la idea de trabajar en la construcción de carreteras a cambio de un asesinato es completamente inadecuada frente a un crimen tan serio como este. Lo rechazamos, pues no llega ni siquiera a estar cerca de lo que pedimos. Insistimos en que las FARC tienen que cooperar con las autoridades en la investigación de este acto de terrorismo internacional y entregar a los responsables. Nada diferente a esto satisface nuestras demandas de justicia (El Tiempo, 29 de mayo de 1999).

En el plano nacional, los pronunciamientos del gobierno estadounidense contribuyeron a arreciar las críticas locales contra la decisión del gobierno de Pastrana de mantener los diálogos con las FARC, a pesar del grave hecho cometido por el grupo armado. En este comunicado vemos la macroteoría planteada por Max Weber (2005), quien afirma:

Una asociación se llama asociación de dominación cuando sus miembros están sometidos a relaciones de dominación en virtud del orden vigente. (...) En el pasado, las asociaciones más diversas - empezando por la familia - emplearon la coacción fisica como medio perfectamente normal. Hoy, en cambio, habremos de decir: el Estado es aquella comunidad humana que en el interior de un determinado territorio - el concepto del "territorio" es esencial a la definición - reclama para sí (con éxito) el monopolio de la coacción fisica legítima. Porque lo específico de la actualidad es que a las demás asociaciones o personas individuales solo se les concede el derecho de la coacción fisica en la medida en que el Estado lo permita. Este se considera, pues, como fuente única del Derecho de Coacción.

\section{CONCLUSIONES GENERALES}

El análisis de 28 registros desde la historicidad del análisis crítico del discurso en la investigación Discursos de la guerra en Colombia 19972005, nos permite concluir que: 
- No hay un acuerdo para denominar el fenómeno que vive el país desde hace más de 50 años, dado que se habla de violencia, de Violencia con mayúscula, de conflicto, de guerra, e incluso en muchos textos se utilizan todas las categorías anteriormente mencionadas a manera de sinónimo. Esto explica que no haya claridad a la hora de definir lo que está sucediendo en Colombia. En el caso colombiano, el Estado no ha logrado ejercer el monopolio estable de la violencia física ni el dominio sobre el territorio durante los últimos 50 años. La guerra no ha sido un fenómeno transitorio que por momentos afecte a los colombianos sino, por el contrario, ha sido un problema endémico sin perspectiva de una solución rápida para el futuro que ha tenido picos propios del momento político que se esté viviendo.

- Si bien la aparición de guerrillas y de otros grupos armados y su paulatino crecimiento dentro del territorio nacional son otra muestra de la falta de monopolio de la violencia por parte del Estado colombiano, la prueba más grande es quizá la subsistencia durante más de medio siglo de estos movimientos en condición de paraestados en muchas regiones del país. En el caso particular de las FARC, desde sus discursos se ve un reconocimiento de la legitimidad del Estado, pero no del monopolio de la fuerza coercitiva de ese Estado. Por esta razón, las farc no tienen inconveniente en reconocer en sus comunicados como algo natural que deben aplicar sus propias leyes en los territorios que son de "su jurisdicción". Las AUc, por su parte, consideran que es el Estado el que debe llenar los vacíos de autoridad que las AUc dejarían con una eventual desmovilización. Esto implica el auto reconocimiento de las AUC como un estamento incluso con mayor legitimidad y poder que el mismo Estado en algunas regiones. Más que arrogancia, demuestra el grado de poder que las AUC lograron tener en varios sectores país. Poder no solo militar, sino también político.

- Resulta paradójico que los gobiernos conservadores, como los de Belisario Betancur y Andrés Pastrana, que suponemos son más cercanos a las Fuerzas Armadas, sean los más proclives a diálogos con las guerrillas y los que se han alejado más de las Fuerzas Armadas en sus decisiones a la hora de firmar sus acuerdos.
Durante los ocho años del mandato de Álvaro Uribe, las relaciones con la guerrilla fueron en algunos momentos turbulentas y en otros, inexistentes. Con los grupos paramilitares fue totalmente distinto. Desde un primer momento se planteó la posibilidad de negociaciones que se fueron desarrollando paulatinamente. De esto dan cuenta, varios comunicados y acuerdos en los cual reiteradamente se expresa confianza en el éxito del proceso.

- En el proceso de paz entre las Farc y el gobierno del presidente Pastrana, y entre el gobierno de Uribe y las AUC, tanto los representantes de los dos gobiernos como los grupos armados demostraron en sus actitudes que el éxito o fracaso del proceso dependía de contingencias. Lo anterior muestra la fragilidad con la que desde un principio se plantearon dichos procesos, fragilidad que los llevó a sendos fracasos. Las evidencias de resquebrajamiento

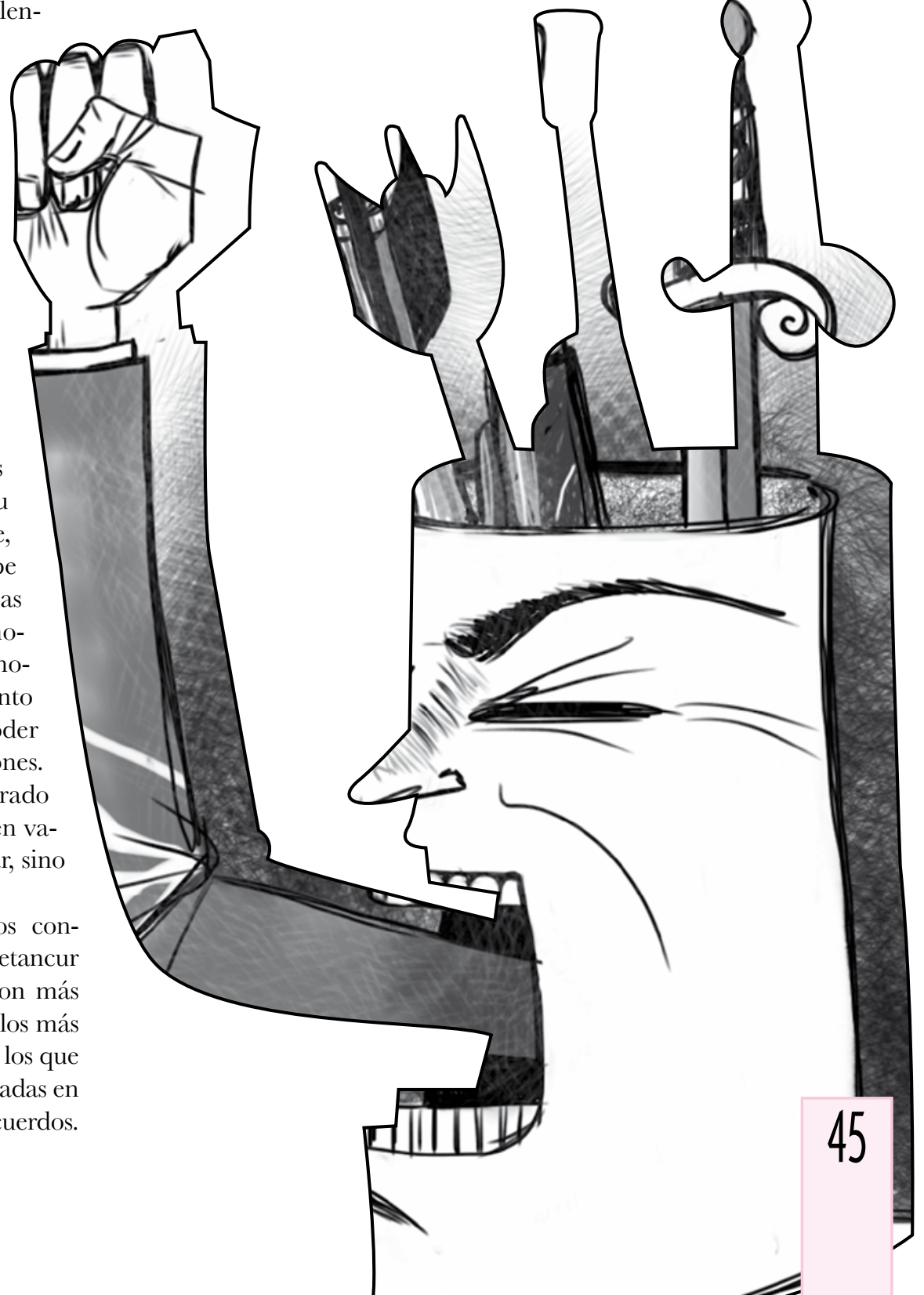


de los Procesos de paz con las FARC y con las AUC se ven por ejemplo en los comunicados y acuerdos que circulan públicamente y que difieren de los hechos que se dan alrededor del proceso.

- La "Zona de Distensión" para las FARC y la promesa de una base jurídica favorable para la desmovilización para las AUC se convierten en una especie de "estímulo" con el cual se premia a estos dos grupos armados. Tanto la "Zona de Distensión" como la promesa de una base jurídica favorable se tornan en armas de doble filo para los gobiernos de Pastrana y de Uribe. Por una parte, sirven como elementos negociadores, pero por otra, debilitan la imagen de soberanía ante los ojos nacionales e internacionales. Para las FARC, el mantenimiento de la "Zona de Distensión" es el pilar de las negociaciones por la necesidad de mantener la autonomía del grupo armado en lo local. Esta autonomía permite por ejemplo el control sobre el cultivo y la comercialización de cultivos ilícitos. Para las AUc, el marco legal para la desmovilización es pilar de las negociaciones por el temor de enfrentar la extradición a Estados Unidos y por la negativa a purgar cárcel.

- Desde el punto de vista internacional, es claro que la caída de las Torres Gemelas es un antecedente que concita a todos los actores discursivos (FARC, AUC, gobierno) a hablar en otro lenguaje. Esto se demuestra por ejemplo en la nominación de la FARC como grupo terrorista por parte de la comunidad internacional que infiltra el discurso del presidente Uribe y de las AUC. El mandatario hace mención constante al terrorismo como fenómeno y a los terroristas como enemigos de la nación. Esta última mención la usa como un argumento para negar cualquier condición política de las guerrillas y, de este modo, justificar la no negociación con las mismas. Las AUC la usan para hacer diferencia entre sus propósitos y los propósitos de las FARC.

- A la hora de analizar el proceso de paz de las FARC y el gobierno de Andrés Pastrana, las AUC ponen al gobierno y a las FARC en un mismo nivel en la balanza en cuanto a sus intenciones de engañar a la población con un proceso de paz que no es viable. Lo mismo ocurre cuando las FARC se refieren al proceso de las AUC con el gobierno de Álvaro Uribe. Sin embargo, tanto el presidente Pastrana como el presidente Uribe creen, o quieren creer que la imagen de sus respectivos gobiernos salen indemnes luego de los procesos de paz fallidos (el tiempo demostraría que no fue de esa manera) y que la única imagen que se deteriora es la de las FARC y las de las AUC. De hecho, Álvaro Uribe nunca admite su fracaso en el proceso con las AUc.

- En la coyuntura electoral posterior a la finalización del proceso de paz entre Pastrana y las FARC hay un cambio de actitud de gran parte de la población frente a la guerra. Los que votaron por Pastrana, porque prometió paz y diálogos, apoyan a Uribe porque promete confrontación directa con las FARC. Desde el primer discurso de posesión de Álvaro Uribe, comienza a mostrar rasgos de neopopulismo: critica a las instituciones porque a su parecer son inoperantes; su discurso está confeccionado con palabras cargadas de emotividad, como patria, patriotas, montaña, etc., que buscan tocar los sentimientos de su auditorio y crear la ilusión de una relación más directa y diáfana con la ciudadanía.

- El discurso de posesión de Álvaro Uribe no permite pensar en ningún momento en el advenimiento de un proceso de negociación con las AUc. El presidente tampoco menciona a este grupo al margen de la ley en ningún momento. Aquí cabría hacerse una pregunta: ¿Cuándo comenzó a gestarse este proceso de negociación?

- La propuesta de las AUC de cese al fuego durante las negociaciones con el gobierno de Uribe busca sin duda marca una distancia grande con las FARC en el proceso de paz con Pastrana y generar confianza en la población sobre sus intenciones sinceras. Las AUC convenientemente se muestran en algunos momentos como un ejército fuerte y unificado y en otros como un grupo dividido. En el primero de los casos, por ejemplo, cuando firman como bloques, hacen gala de su poder de movilización de hombres. En el segundo de los casos, por ejemplo cuando firman como individuos o hablan en nombre propio -como es el caso de Castaño o Mancuso-, quieren eludir la responsabilidad como organización por los actos que algunas facciones puedan cometer.

- La mención permanente de entes de prestigio y poder, como la iglesia y de entidades supranacionales, buscó siempre blindar los procesos de negociación con las FARC y las AUC y darles legitimidad a dichos procesos.

- El estilo de los comunicados de las AUC cambia a partir de la ausencia de Carlos Castaño. Se percibe un tono menos beligerante y se deja de lado el cambio indistinto de primera 
persona del singular a primera persona del plural. Lo anterior nos puede hacer pensar en que las decisiones entre las Auc se empiezan a tomar de manera más concertada luego de la muerte de Castaño.

- En varios de sus comunicados, las AUC reconocen su cercanía ideológica con Álvaro Uribe Vélez y se autorreferencian como héroes salvadores que suplen la falta de presencia del Estado. Entre tanto, las FARC se autorreferencian como opositores al Estado, sin importar cual sea el gobierno que esté en el poder.

\section{REFERENCIAS BIBLIOGRÁFICAS}

\section{Libros}

Arocha, Jaime (1979). La Violencia en el Quindío. Bogotá: Tercer Mundo editores.

Braudel, Fernand (2006). "La larga duración", en Revista Académica de Relaciones Internacionales, Núm. 5 Noviembre de 2006, UAM-AEDRI.

Facultad de Ciencias Sociales Universidad de Los Andes (1999). Los Laberintos de la Guerra. Utopías e incertidumbres sobre la paz. Bogotá: Tercer Mundo Editores.

IEPRI (1987). Colombia, violencia y democracia. Informe presentado al Ministerio de Gobierno. Comisión de estudios sobre la violencia. Bogotá: Universidad Nacional de Colombia.

Comisión de Superación de la Violencia (1991). Informe del Consejero de Paz y Derechos Humanos de la Presidencia de la República. Bogotá: Presidencia de la República.

Comisión de Superación de la Violencia (1992). Pacificar la Paz - Lo que no se ha negociado en los Acuerdos de Paz. Bogotá: IEPRI-CINEPCAJ- CECOIN.

Corporación Nuevo Arco Iris (2007). Parapolítica, la ruta de la expansión paramilitar y los acuerdos políticos. Bogotá: Intermedio editores.

Dix, Robert (1967). Colombia the political dimensions of the change. Connecticut: Yale University Press, New Haven.

Echandía Castilla, Camilo (2006). Dos décadas de escalamiento del conflicto armado en Colombia 1986-2006. Bogotá: Universidad Externado de Colombia.

Elias, Norbert (2006). El proceso de la Civilización. Madrid: Editorial Universidad de Navarra.

Fairclough, N. (1989). Language and power. London: Addison Wesley Publishing Company.

Ferro Medina, Juan Guillermo y Graciela Uribe Ramón (2002). El orden de la guerra - Las FARC-EP: Entre la organización y la política. Bogotá: Centro Editorial Javeriano.

Foucault, Michel (2003). La arqueología del Saber. Buenos Aires: Siglo XxI editores.
Foucault, Michel (1970). El orden del discurso. Barcelona: Tusquets Editores.

Foucault, Michel (1992). Microfisica del poder. Buenos Aires: Ediciones de La Piqueta.

Foucault, Michel (1992). Saber y verdad. Buenos Aires: Ediciones de La Piqueta.

Gaviria, José Obdulio (2005). Sofismas del terrorismo en Colombia. Bogotá: Editorial Planeta.

GIRALDO, Jorge (2009). Guerra civil posmoderna. Bogotá: Siglo del Hombre Editores.

González, Fernán; Ingrid Bolívar y Teófilo Vásquez (2004). Violencia política, de la nación fragmentada a la construcción del Estado. Bogotá: cineP.

González, Fernán (1997). Para leer la política, ensayos de historia política colombiana. Bogotá: CINEP/ Ediciones Antropos.

GonzÁlez, Fernán y otros (1997). Violencia en la región Andina, el caso Colombia. Bogotá: CINEP/ Ediciones Antropos.

Grupo de Memoria Histórica de la Comisión Nacional de Reparación y Reconciliación (2010). Bojayá, la guerra sin límites. Bogotá: Editorial Taurus, Fundación Semana.

GonzÁLEz, Fernán; Ingrid Bolívar y Teófilo Vásquez (2002). Violencia política en Colombia: de la nación fragmentada a la construcción del Estado. Bogotá: cINEP.

GonzÁlez, Victoria E. (2007). "Las palabras en la guerra", en Revista Comunicación y Ciudadanía. Bogotá: Facultad de Comunicación Social-periodismo. Universidad Externado de Colombia.

Hobsbawm, Eric (2000). Bandidos. Barcelona: Editorial Crítica.

Hobsbawm, Eric (2001). Rebeldes primitivos. Barcelona: Editorial Crítica.

IEPRI (2006). Nuestra guerra sin nombre, transformaciones del conflicto armado en Colombia. Bogotá: Editorial Norma.

IEPRI (2006). En la encrucïada, Colombia en el Siglo XXI. Bogotá: Editorial Norma.

Kalyvas, N. Stathis (2006). The logic of violence in civil war. Cambridge: Cambridge University Press.

KrzyzanOwski Michael \& Ruth Wodak (2007). "Multiple Identities, Migration, and Belonging: Voices of Migrants" in Carmen CaldasCoulthard \& Rick Iedema (Eds.) Identity Troubles. Basingstoke.

Munkler, Herfried (2005). Viejas y nuevas guerras: Asimetría y privatización de la violencia. Siglo xxi de España Editores.

PArdo, Neyla (2007). Cómo hacer análisis crítico del discurso. Una perspectiva latinoamericana.. Santiago de Chile: Editorial Frasis.

Pecaut, Daniel (2003). Orden y Violencia. Evolución sociopolítica de Colombia entre 1930 y 1953. Bogotá: Grupo Editorial Norma. 
